\title{
LA VIRTUALIDAD \\ EN LA GALERÍA DE ARTES VISUALES DE LA URP
}

Extrañamos las inauguraciones de exposiciones en la Galería de Artes Visuales. No sabemos cuánto tiempo dure la pandemia, pero dentro de los medios a nuestro alcance nos hemos tenido que atener al uso de la virtualidad. Este medio, que ha conquistado nuestra mirada enajenada, debería servir para asuntos más relevantes, como descubrir el trabajo de los hombres y mujeres que se dedican al arte, por ejemplo. ¿Sabemos qué piensan los artistas a raíz de la pandemia que sufrimos? ¿Cómo coordina la creación con las necesidades de la vida diaria? Lo bueno de las exposiciones es que nos presenta lo que piensa el artista, aunque a veces pinte abstracciones, y nos da la oportunidad de conocer más de él y del estilo que practica. Aprovechemos esta larga pandemia para pensar en las cosas que nunca se nos ocurrió pensar: El arte refleja como un espejo lo que es el hombre, sus búsquedas, sus dudas, la vida y la muerte. Escuchemos sus voces a través de sus cuadros.

\section{Alfonso Castrillón Vizcarra}

Director de la Galería de Artes Visuales 


\section{CIUDAD CANSADA}

Nelson Flores

Julio, 2018
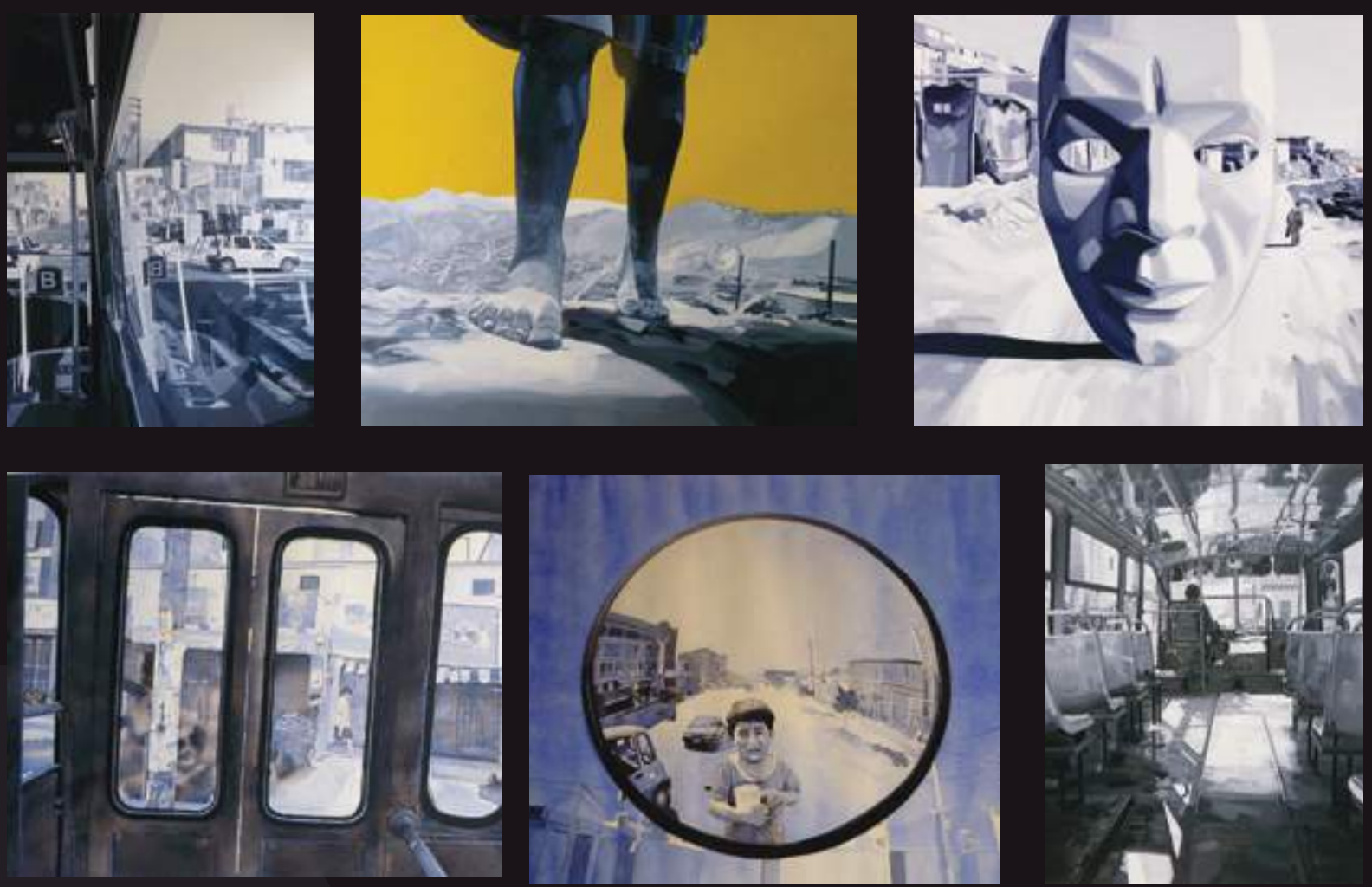

DESCIFRANDO UN ESPEJISMO

Maroé Susti

Agosto, 2018
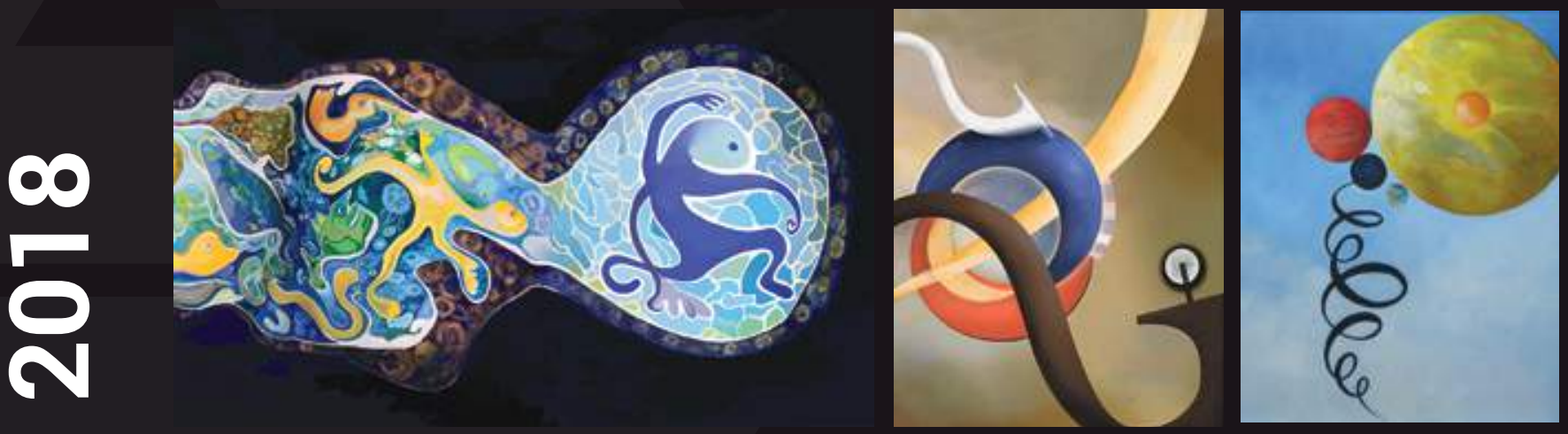

\begin{tabular}{l}
$\frac{0}{c}$ \\
$\frac{0}{0}$ \\
$\frac{0}{0}$ \\
$\frac{0}{x}$ \\
\hline
\end{tabular}
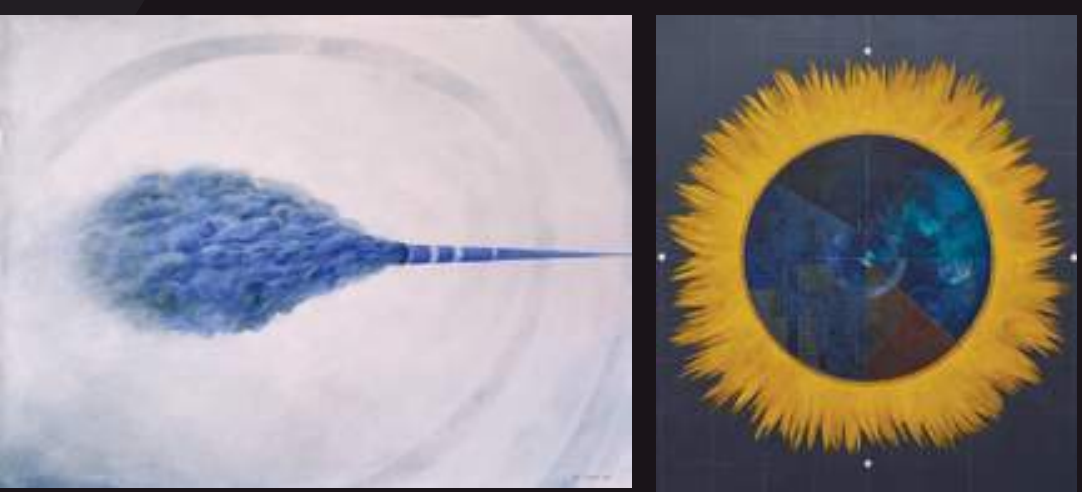
10 AÑOS DE XILOGRAFÍA

Luis Antonio Torres Villar

Abril, 2019
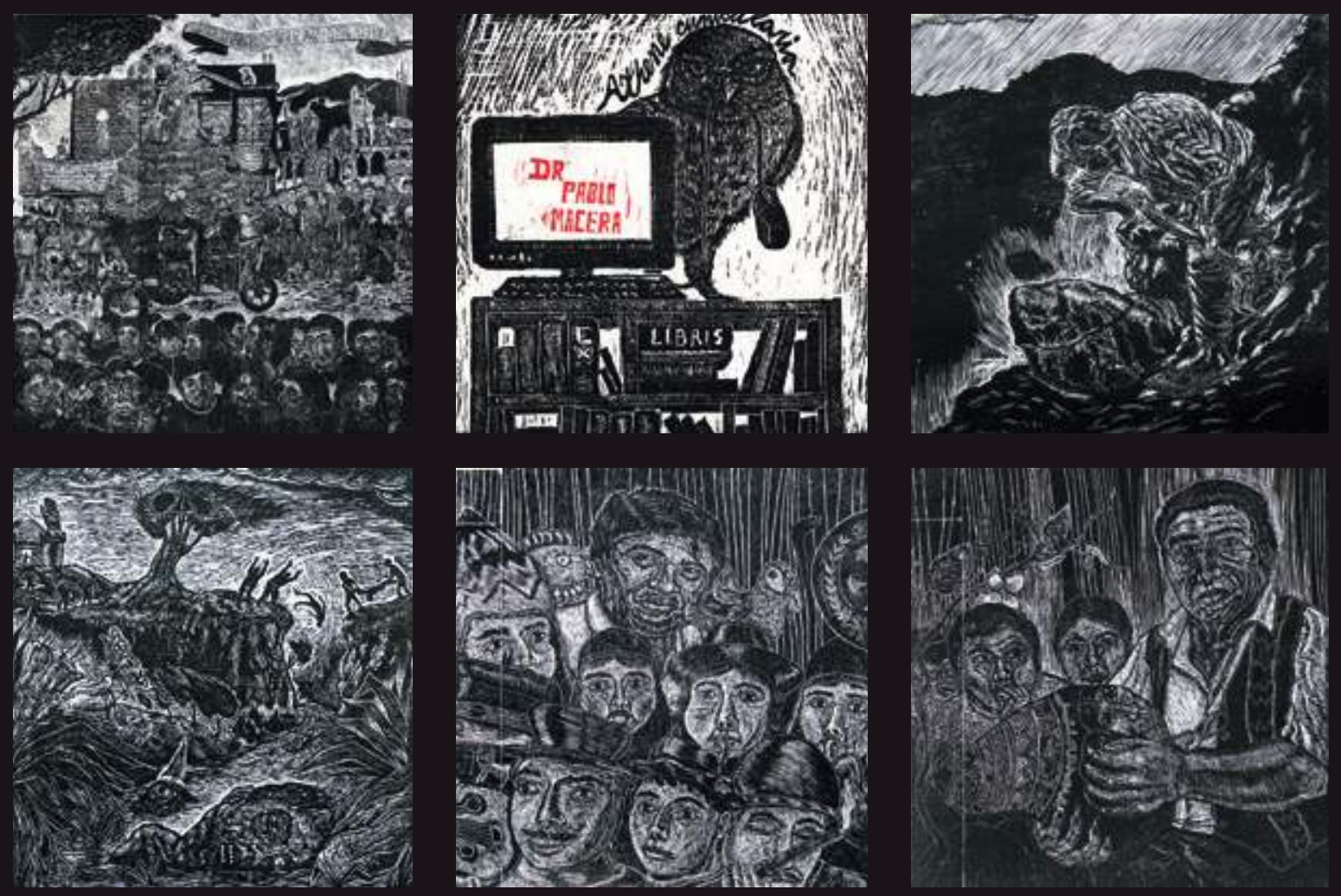

\section{CINCO APUESTAS FIGURATIVAS}

Gala - Karina - Gloria - Salima - Judith

Marzo, 2019
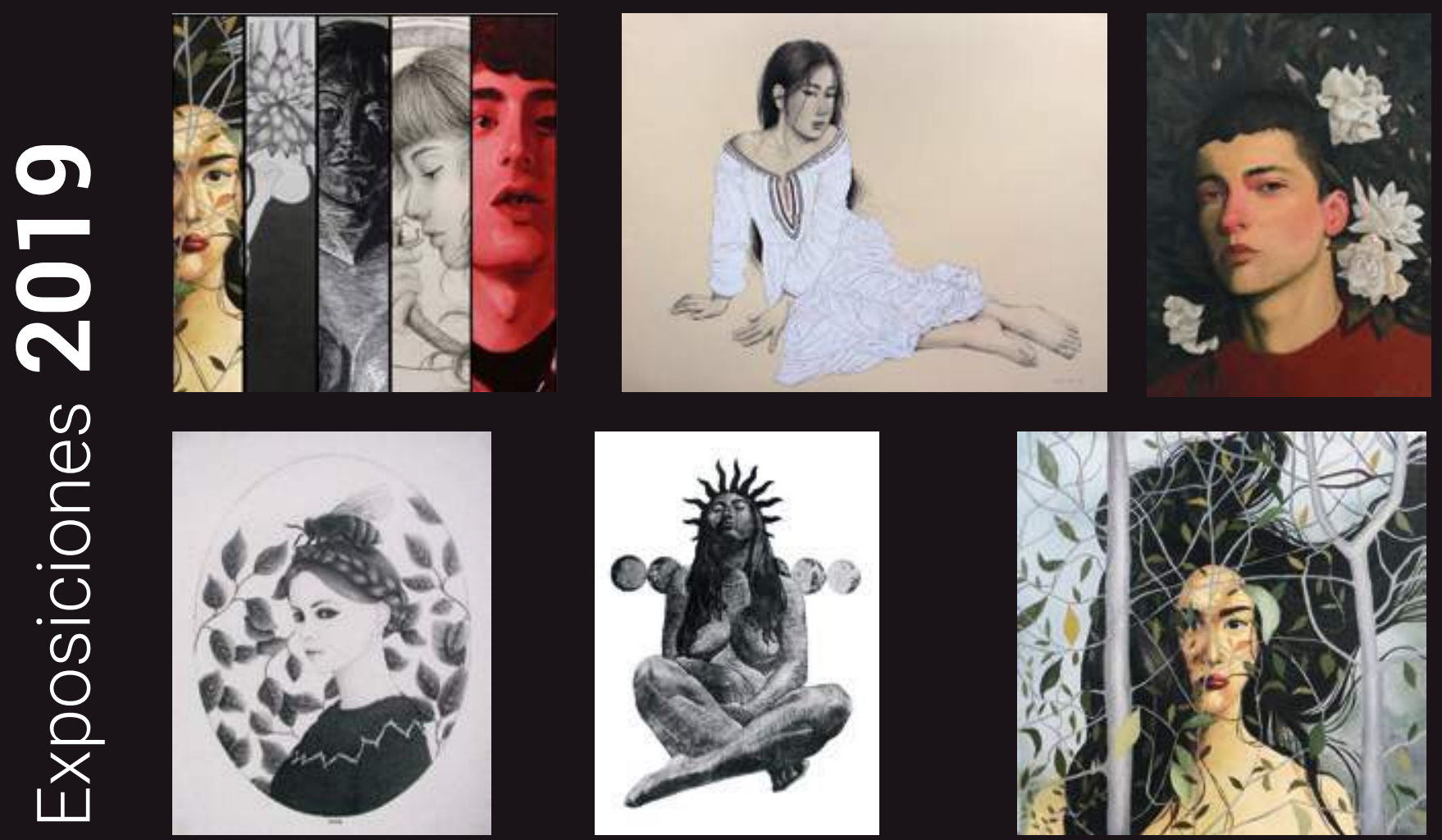


\section{DISEÑO GRÁFICO - PIONEROS DE LOS SESENTA}

González - Ruiz Durand - Dieterich - Santa Cruz - Palacios - Escalante Mayo, 2019
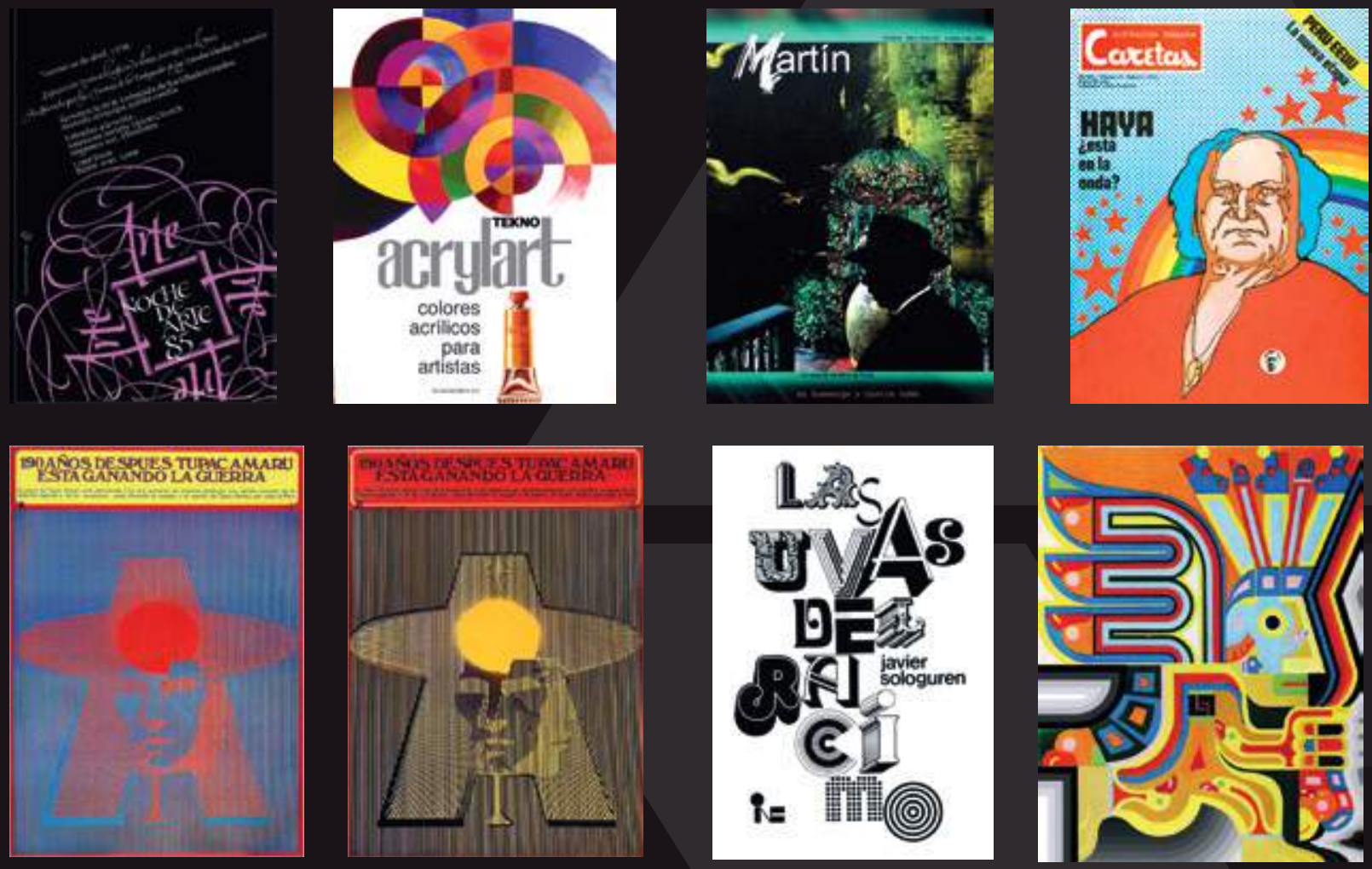

TESTIMONIO DE VIDA ARTÍSTICA - HOMENAJE A LA BAUHAUS Rolf Bertschat Junio, 2019
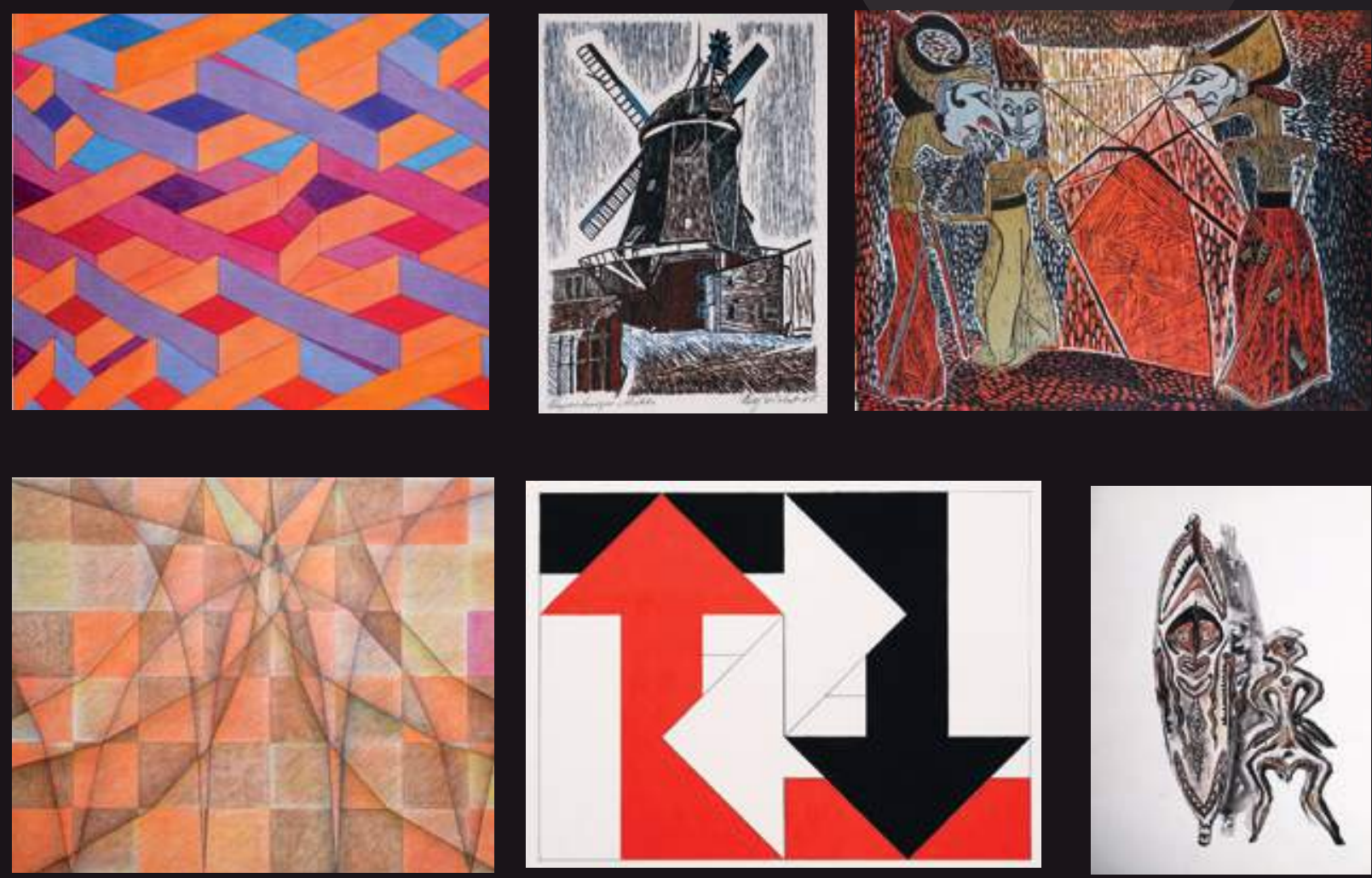
DE TRADICIONES Y GESTIONES-EL LEGADO DE RICARDO PALMA A LA SOCIEDAD PERUANA

GAV- Galería de Artes Visuales

Setiembre, 2019
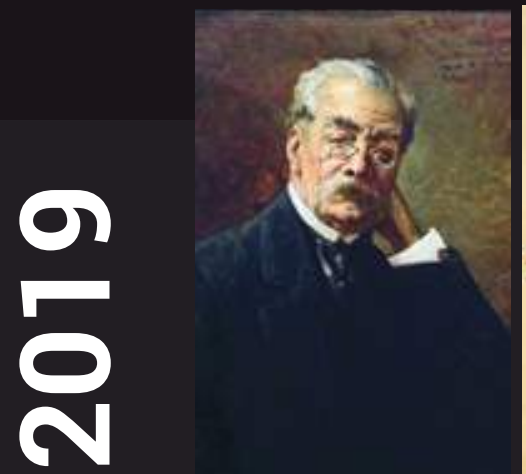
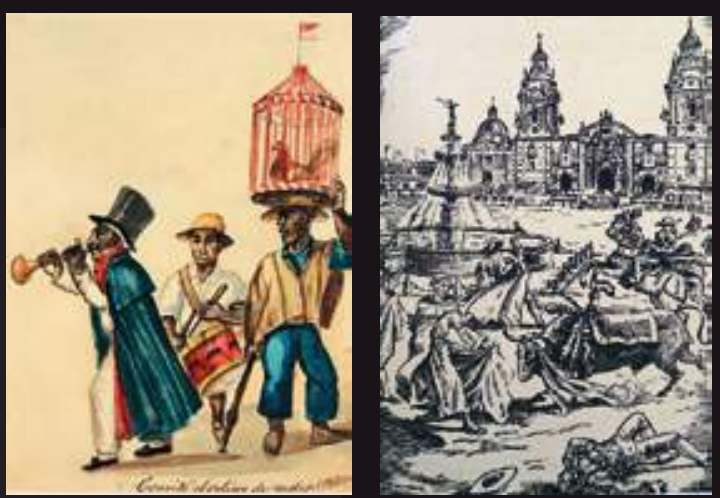

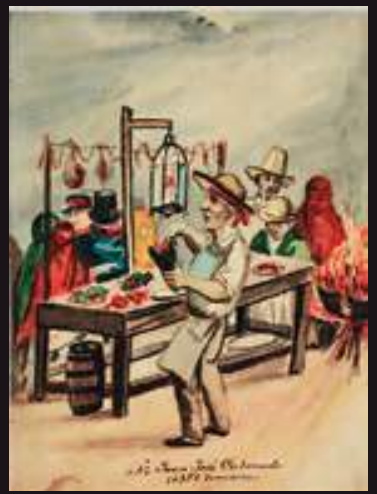

\begin{tabular}{l}
$\frac{0}{\complement}$ \\
$\frac{0}{0}$ \\
$\frac{0}{0}$ \\
$\frac{0}{x}$ \\
\hline
\end{tabular}
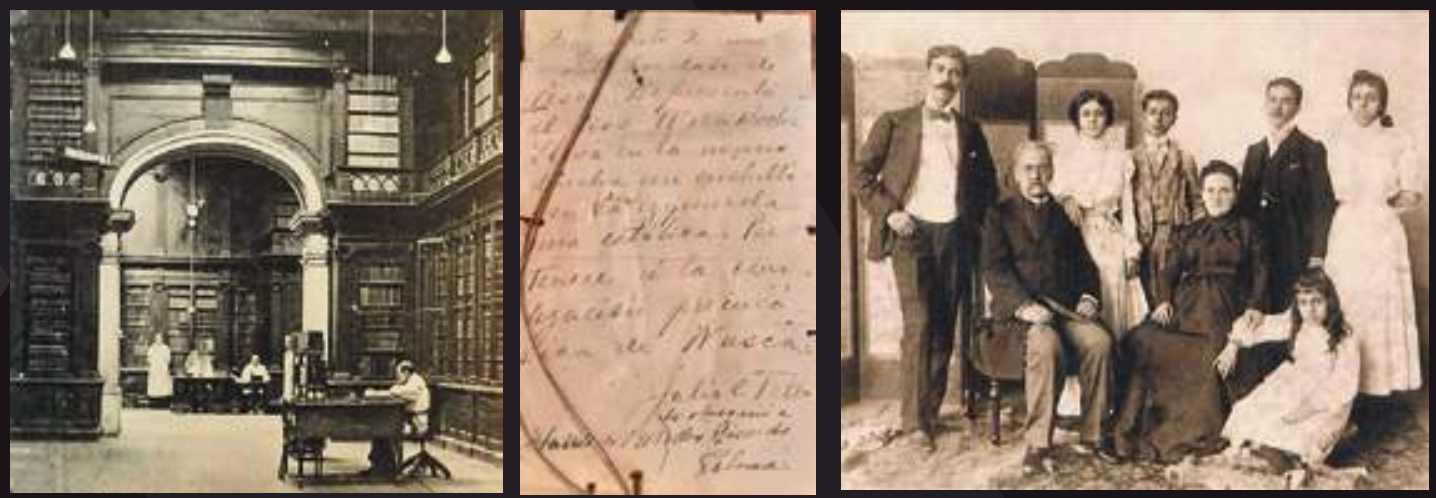

PERÚ AL PIE DEL ORBE II Bruno Portuguez Nolasco Enero, 2020
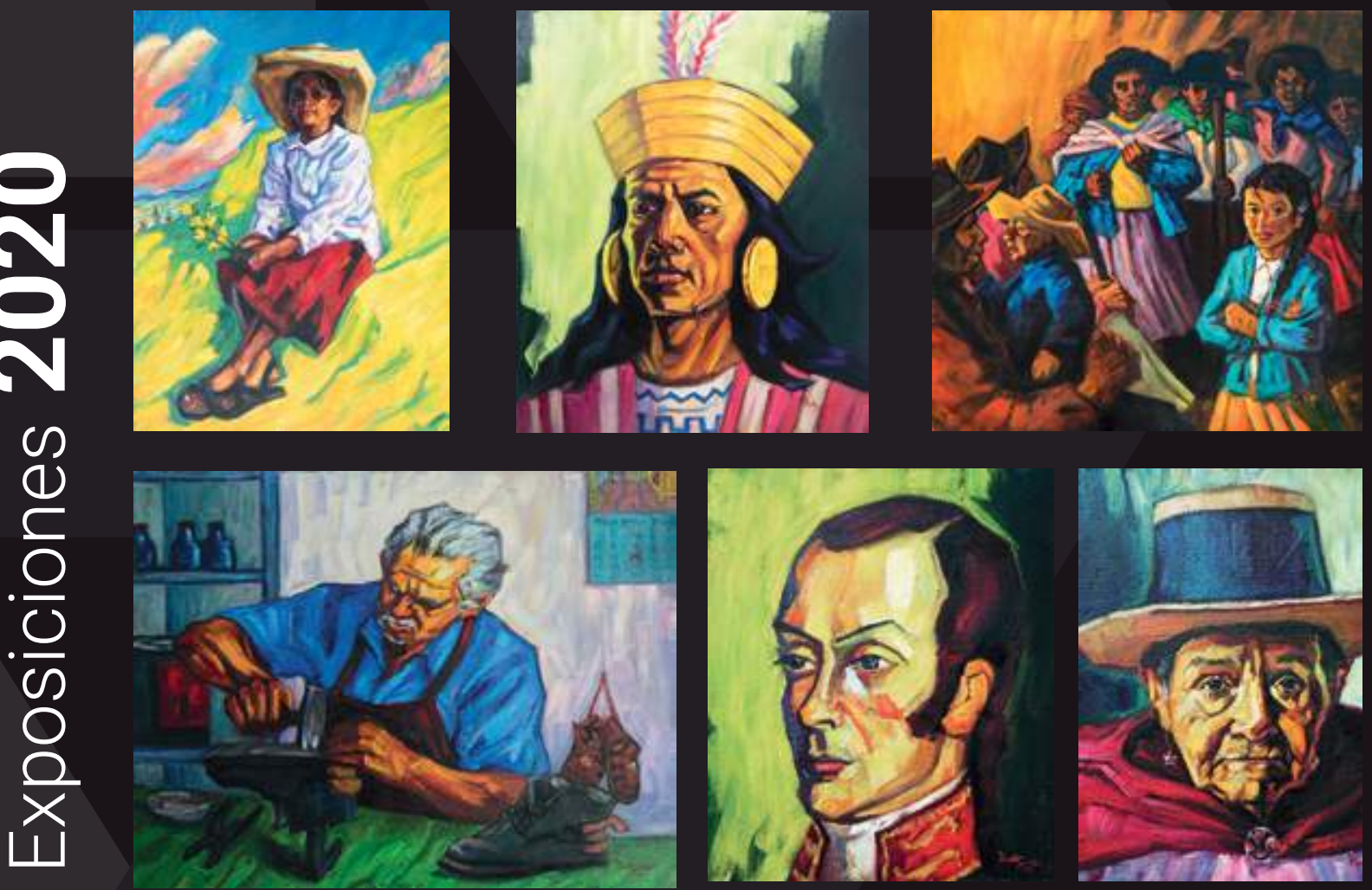


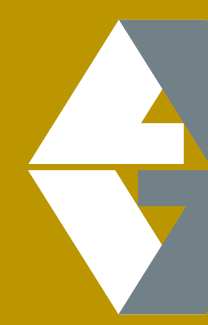

El arte refleja como un espejo

lo que es el hombre,

sus búsquedas,

sus dudas,

la vida y la muerte...

Alfonso Castrillón Vizcarra 